\title{
Surgical treatment of left main and left anterior descending artery ectasia with fistula to right ventricle
}

Turki B. Albacker, MBBS, MSc, FRCSC, FACS, FACC, ${ }^{a}$ Rakan Barghouthi, MBBS, ${ }^{\mathrm{a}}$ Fathi Zahran, MD, ${ }^{\mathrm{a}}$ and Nasser Aljerayed, MBBS ${ }^{\mathrm{b}}$

From the ${ }^{\mathrm{a} C a r d i a c}$ Sciences Department, College of Medicine, King Saud University; and ${ }^{\mathrm{b}}$ Cardiac Surgery Department, King Saud Medical City, Riyadh, Saudi Arabia.

Disclosures: The authors reported no conflicts of interest.

The Journal policy requires editors and reviewers to disclose conflicts of interest and to decline handling or reviewing manuscripts for which they may have a conflict of interest. The editors and reviewers of this article have no conflicts of interest.

Received for publication Jan 31, 2020; revisions received Jan 31, 2020; accepted for publication Feb 28, 2020; available ahead of print March 6, 2020.

Address for reprints: Turki B. Albacker, MBBS, MSc, FRCSC, FACS, FACC, Cardiac Sciences, College of Medicine, King Fahad Cardiac Center, King Saud University, Riyadh, Saudi Arabia (E-mail: talbacker@ksu.edu.sa). JTCVS Techniques 2020;2:70-2

2666-2507

Copyright (C 2020 The Authors. Published by Elsevier Inc. on behalf of The American Association for Thoracic Surgery. This is an open access article under the CC BY-NC-ND license (http://creativecommons.org/licenses/bync-nd/4.0/).

https://doi.org/10.1016/j.xjtc.2020.02.031

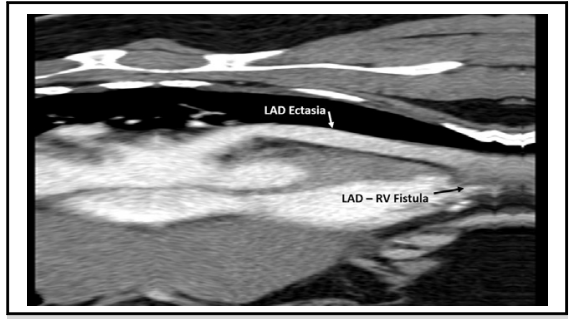

Ectasia of LM and LAD coronaries with fistula to RV.

CENTRAL MESSAGE

LM and LAD artery ectasia with

fistula to right ventricle was

treated with fistula outflow

closure only and long-term

anticoagulation.

See Commentaries on pages 73 and 75 .
Aneurysmal coronary artery disease (ACAD) is a very rare congenital anomaly, with an incidence of $0.15 \%$ to $4.9 \%$ of patients undergoing coronary angiography. ACAD is categorized into coronary artery aneurysms or coronary artery ectasia (CAE). CAEs are further classified based on their topographic extent into 4 types ranging from diffuse dilatation in multiple coronary arteries (type I) to a localized segmental ectasia of one artery (type IV). ${ }^{1}$

Coronary artery fistulas, in contrast, are rarer than ACAD, with an estimated frequency of $0.27 \%$ to $0.4 \%$ of all congenital cardiac lesions, ${ }^{2}$ and the combination of both pathologies is very rare and occurs commonly in younger patients. Most coronary fistulas are congenital in origin and may arise from many sites. The more proximal the site where the feeding artery arises from the main coronary artery, the more dilated the feeding artery tends to be. ${ }^{3}$ Fistulas originate from the right coronary artery in $52 \%$ of cases, the left anterior descending artery in 30\% of cases, and the left circumflex artery in $18 \%$ of cases. ${ }^{4}$ Most coronary fistulas $(90 \%)$ present with signs and symptoms of volume overload and drain to the right cardiac chambers.

We report here a case of CAE of the left anterior descending artery (LAD) associated with distal coronary fistula to right ventricle (RV) that was misdiagnosed as apical ventricular septal defect (VSD) and show its management with 2 years' follow-up.

\section{CASE DESCRIPTION}

This is a case of 28-year-old female patient who presented with shortness of breath on exertion, New York Heart Association class I that progressed to class III over a 12-month period. She denied any history of chest pain, orthopnea, or paroxysmal nocturnal dyspnea. She had no other medical problems. She underwent echocardiogram, which revealed an apical VSD measuring $1.5 \times 1.0 \mathrm{~cm}$ with left to right shunt and no significant pulmonary hypertension. The shunt ratio Qp/Qs was 2.5. The echocardiogram also showed mildly depressed left ventricular function (LVF) with an ejection fraction of $45 \%$ with no specific wall motion abnormalities but rather generalized hypokinesia.

The decision was made to perform a surgical closure of the VSD, and the patient was counseled and accepted the surgery. Intraoperatively, there was a diffuse aneurysmal dilatation of the LAD extending from the left main coronary artery all the way to the apex. There was no evidence of scarring on the anterior wall. We placed the patient on cardiopulmonary bypass through a routine aortic arterial and bicaval venous cannulation and proceeded with the initial plan to close the VSD. After arresting the heart and performing an apical right ventriculotomy, we identified 


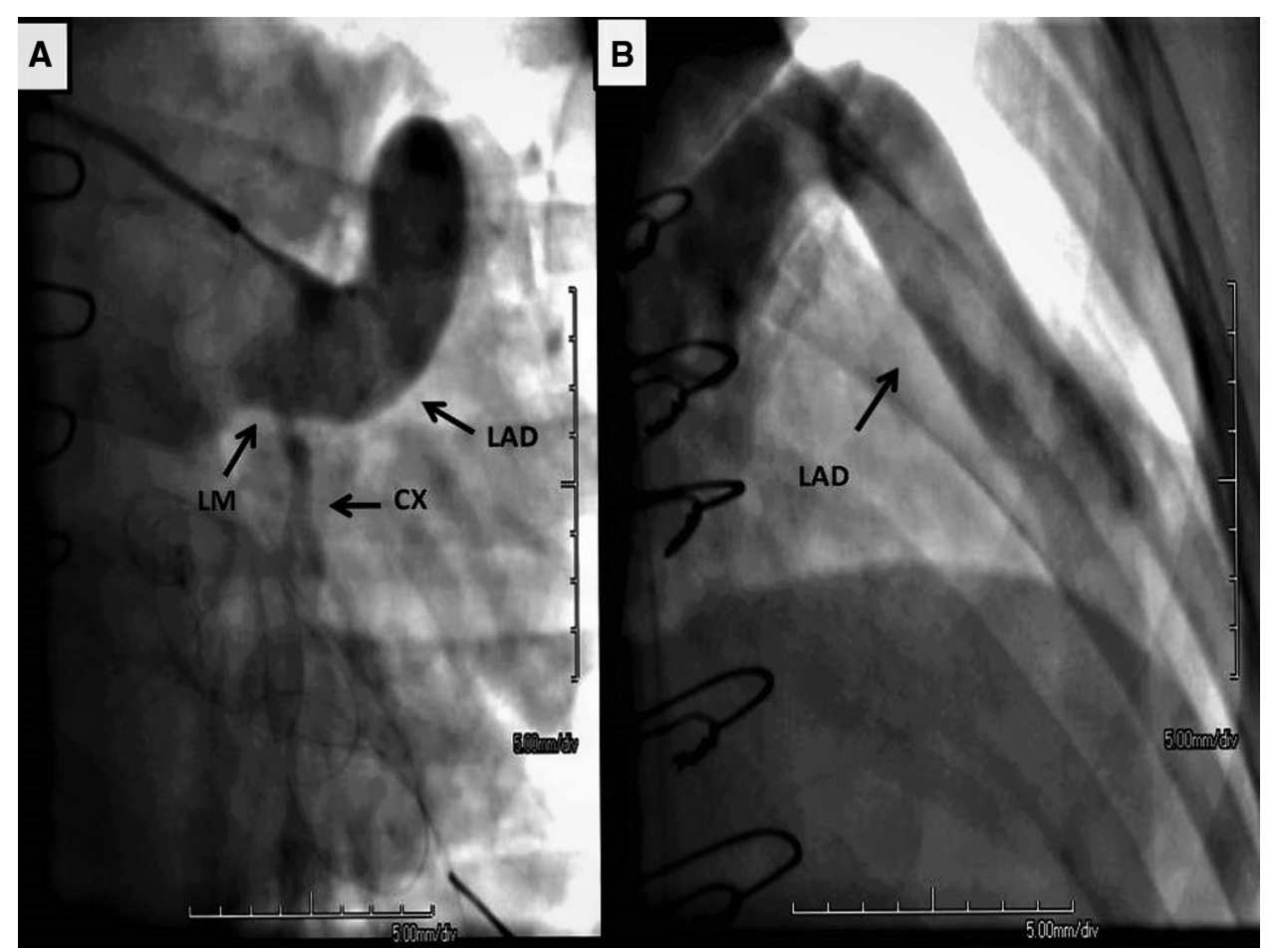

FIGURE 1. Coronary angiogram of a patient with LAD artery fistula to the RV that is associated with diffuse ectasia of the LM and LAD coronary arteries. A, Right anterior oblique caudal view showing the ectatic LM coronary and proximal LAD with a normal left CX artery. B, Right anterior oblique cranial view showing the LAD ectasia. $L A D$, Left anterior descending; $L M$, left main; $C X$, circumflex.

the defect and we probed it and, surprisingly, it was communicating with the distal part of the LAD and not the left ventricle. We decided to close the defect with a bovine pericardial patch from the RV side and then we closed the right ventriculotomy in routine fashion. The patient came off bypass easily and was transferred to the intensive care unit in stable condition and subsequently had an uneventful postoperative course.

Before discharge, the patient underwent coronary angiography, which confirmed the presence of left main (LM) and LAD ectasia type III (Figure 1) with the LAD measuring $1.5 \mathrm{~cm}$ in diameter and no communication with the RV. The patient was anticoagulated with warfarin, keeping a target international normalized ratio of 2.0 to 2.5 , and was discharged home. She underwent a follow-up echocardiogram at 6 months that showed recovery of the LVF to $60 \%$. She also had a cardiac computed tomography followup at 2 years that showed stability of the size of the LM and LAD arteries and no communication with any cardiac chamber (Figure 2). She remained asymptomatic at her last follow-up at 2 years, with life-long anticoagulation. The patient(s) provided informed consent for the publication of study data.

\section{DISCUSSION}

Both the indication and technique for surgical repair of coronary aneurysms are controversial. Coronary size of at least 3 to 4 times the original vessel diameter is an absolute indication for operation based on previous reports of coronary aneurysm rupture when the diameter exceeded $30 \mathrm{~mm} .{ }^{5}$ Different techniques has been described to address coronary aneurysms, including plication of the aneurysm, resection, primary closure of the proximal and distal necks of the aneurysm with a suture, and closure with a woven Dacron patch. The artery distal to the aneurysm is addressed with an interpositioning graft or a vein bypass to the distal vessel. When a fistula is present, both inflow and outflow of the fistula should be ligated.

In our case, the patient was misdiagnosed preoperatively as an apical VSD and because she was young, we did not perform a preoperative coronary angiography (Video 1). That precluded us from fully understanding the anatomy of the coronary arteries and its ectatic segments and also we did not know the communications of the fistula. Therefore, based on the known information to us, we elected to just close the outflow of the fistula to the RV with a pericardial patch to get rid of the volume overload to the pulmonary circulation. Once the anatomy of the coronaries were clarified with the postoperative coronary angiography, we thought that, given the diffuse nature of the ectasia of the $\mathrm{LM}$ and LAD, it was impossible to excise it or to ligate the fistula inflow which is the ostium of the LM in our case that would lead to death. Therefore, the decision was made to leave it alone and just to begin the patient on 


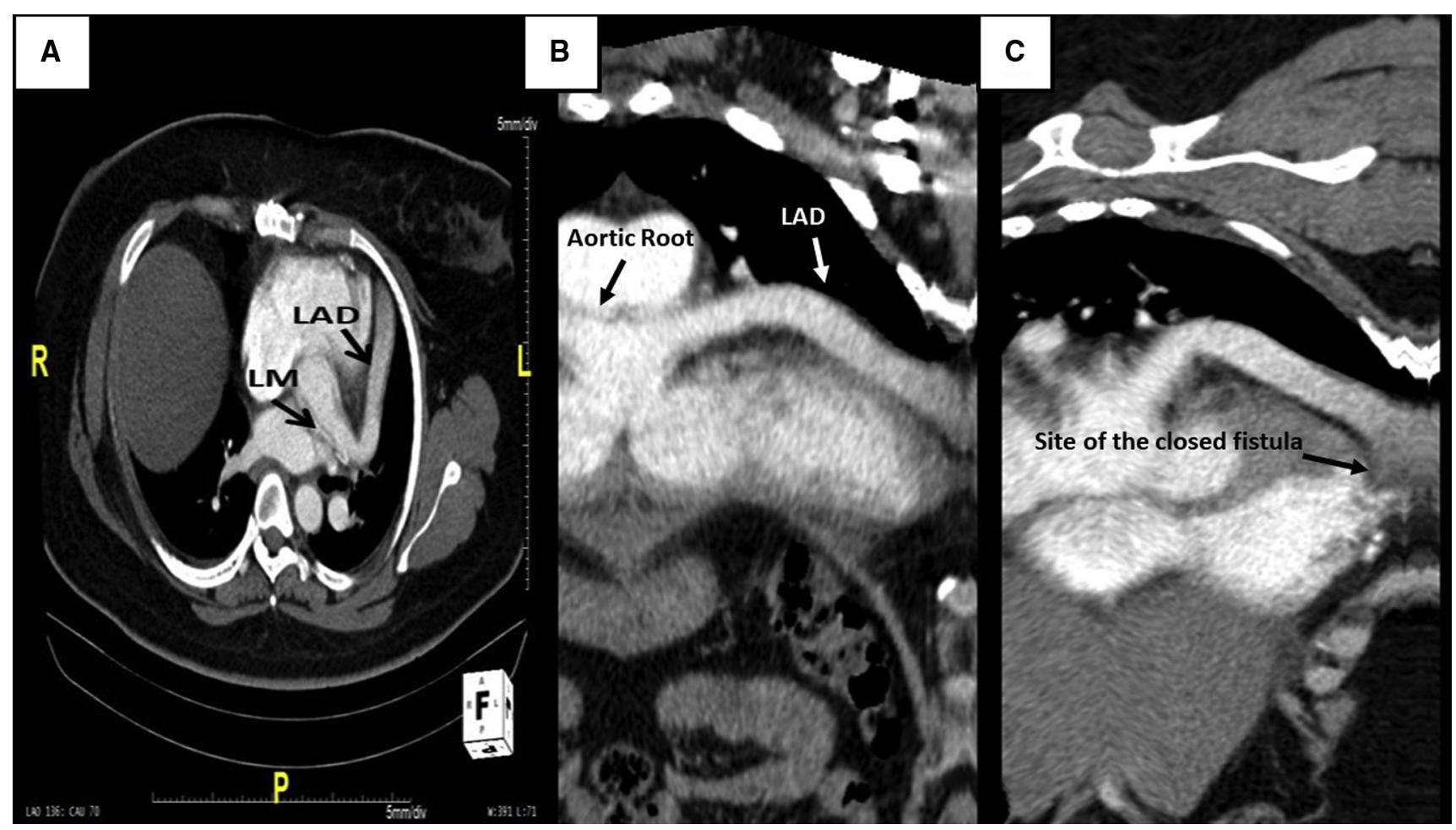

FIGURE 2. Computed tomography of the chest with contrast 2 years after the ligation of the LAD artery to RV fistula outflow. A, Axial view showing the ectatic LM coronary artery and the proximal and mid-LAD with no increase in its size. B, Reconstructed sagittal view showing the aortic root and the course of the ectatic LM and LAD in the interventricular groove. C, Rotated foreshortened sagittal view showing the area of closed LAD-RV fistula. LAD, Left anterior descending; $L M$, left main.

life-long anticoagulation. The 2-year follow-up showed that the patient stayed clinically free of symptoms and recovered her LVF and radiologically had stabilization of the size of the LM and LAD coronary artery.

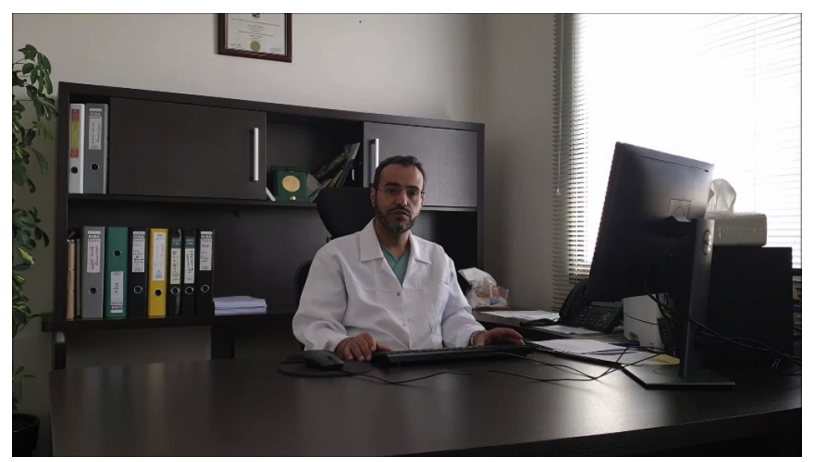

VIDEO 1. Dr Turki Albacker explaining the important aspects of the case and the rationale for not excluding the ectatic artery surgically and not closing the entry point of the left anterior descending-right ventricle fistula. Video available at: https://www.jtcvs.org/article/S2666-2507(20)30139-5/ fulltext.

\section{CONCLUSIONS}

This is a challenging case of LM and LAD ectasia with a fistula to the RV causing a steal syndrome and misdiagnosed as a VSD. We showed in this case that type III CAE with fistula could be treated with closure of the fistula outflow only and long-term anticoagulation for the CAE. This is a simple repair of a complex problem that resulted in recovery of the LV function and excellent short- and intermediate-term outcomes.

\section{References}

1. Markis JE, Joffe CD, Cohn PF, Feen DJ, Herman MV, Gorlin R. Clinical significance of coronary arterial ectasia. Am J Cardiol. 1976;37:217-22.

2. Liberthson RR, Sagar K, Berkoben JP, Weintraub RM, Levine FH. Congenital coronary arteriovenous fistula. Report of 13 patients, review of the literature and delineation of management. Circulation. 1979;59:849-54.

3. Qureshi SA. Coronary arterial fistulas. Orphanet J Rare Dis. 2006;1:51.

4. McNamara JJ, Gross RE. Congenital coronary artery fistula. Surgery. 1969;65: 59-69.

5. Biglioli P, Alamanni F, Antona C, Agrifoglio M, Spirito R. Aneurysms of the coronary arteries: one case report. Thorac Cardiovasc Surg. 1988;36: $239-40$. 